\title{
Analisis Perbandingan Kalkulasi Manual Fuzzy Logic Metode Mamdani Dan Tsukamoto Pada Penentuan Tipe Diabetes Melitus
}

\author{
Rico Adrial ${ }^{1}$, Vitriani ${ }^{2}$, Sri Rahayu Alfitri Usna ${ }^{3}$ \\ Program Studi Fisika Universitas Andalas, Padang, Sumatera Barat (1 dan 3) \\ Kampus Unand Limau Manis, Pauh, Padang \\ Program Pendidjkan Teknik Informatika, Pekanbaru, Riau \\ 1 ricoadrial@sci.unand.ac.id \\ $3 \underline{\underline{\text { sirahayualfitiani@ } @ \text { umri.ac.id }}} \underline{\underline{\text { sci.unand.ac.id }}}$
}

\begin{abstract}
Abstrak
Terdapat beberapa metode pada Fuzzy Logic diantaranya Mamdani dan Tsukamoto. Kedua metode ini memiliki hubungan yang menarik dimana output yang dihasilkan ditampilkan dalam bentuk grafik akan tetapi dengan kalkulasi yang berbeda. Artikel ini akan menjabarkan bagaimana perbandingan antar kedua metode tersebut dalam kasus penentuan tipe diabetes melitus. Diabetes itu sendiri terdiri atas dua tipe, dimana perbedaan antara kedua tipe tersebut sering terabaikan. Penggunaan fuzzy logic menggunakan metode Mamdani lebih optimal dalam kasus penentuan tipe diabetes dibandingkan dengan metode Tsukamoto. Hasil kalkulasi manual menunjukan bahwa metode Mamdani lebih mendekati keadaan yang sebenarnya. Berdasarkan kalkulasi yang telah dilakukan perbedaan hasil keluaran yang signifikan ini disebabkan oleh beberapa hal, yaitu Output yang ada pada Tsukamoto hanya berkisar pada nilai 45 sampai dengan 55. Hal ini membuat jika sedikit saja kalkulasi salah maka hasil yang diperoleh akan berdampak besar. Sedangkan hal ini tidak akan berlaku pada metode Mamdani.
\end{abstract}

Kata kunci : Fuzzy Logic, Mamdani, Tsukamoto, Diabetes Mellitus

\begin{abstract}
There are several methods on Fuzzy Logic, including Mamdani and Tsukamoto. Both of these methods have a satisfying relationship where the resulting output is displayed in the form of graphs but with different calculations. This article will describe how the comparison between the two methods in the case of determining the type of diabetes mellitus. Diabetes itself consists of two types, where the difference between the two types is often overlooked. The use of fuzzy logic using the Mamdani method is more optimal in the case of determining the type of diabetes compared with Tsukamoto method. Manual calculation results indicate that Mamdani's methods are closer to the actual state. Based on the calculations that have been done this significant output difference is caused by several things, namely the Output in Tsukamoto only ranges from the value of 45 to 55. This makes if the calculation is very slight and the results will have a big impact. This will not apply to the Mamdani method.
\end{abstract}

Keywords: Fuzzy Logic, Mamdani, Tsukamoto, Diabetes Mellitus

\section{Pendahuluan}

Fuzzy Logic adalah salah satu metodologi sistem pendukung keputusan yang cocok untuk diimplementasikan pada pemilihan tipe diabetes. Hal ini dikarenakan fuzzy logic merupakan sistem yang dapat menghitung dan memutuskan dengan baik. Fuzzy Logic atau Logika Fuzzy merupakan salah satu metode untuk menentukan sebuah keputusan. Saat logika 
klasik menyatakan bahwa segala hal dapat dinyatakan dengan pilihan 0 atau 1 , hitam atau putih serta ya atau tidak, logika fuzzy menggantikan pilihan tersebut dengan tingkat kebenaran. Logika Fuzzy memungkinkan nilai keanggotaan antara 0 dan 1, tingkat keabuan dan juga hitam dan putih, dan dalam bentuk linguistik, konsep tidak pasti seperti "sedikit", "lumayan", dan "sangat". Terdapat beberapa metode pada Fuzzy Logic diantaranya Mamdani dan Tsukamoto.

Metode Mamdani dan Tsukamoto merupakan dua metode fuzzy Inference system pada logika fuzzy untuk pengambilan keputusan. [1] Kedua metode tersebut memiliki perbedaan pada mesin inferensi fuzzy dan pendekatan defuzzyfikasi. Fuzzyfikasi adalah proses mengubah nilai masukan tegas menjadi nilai masukan fuzzy. Nilai masukan untuk kedua metode ini sama tetapi akan berbeda dalam hal defuzzyfikasi.

Diabetes Melitus adalah suatu penyakit dimana gula darah meningkat akibat tubuh yang tidak menghasilkan hormon insulin yang cukup atau hormon tersebut tidak bekerja dengan baik. Padahal hormon insulin ini berperan penting dalam mengatur kadar glukosa di dalam darah. Diabetes melitus itu sendiri memiliki arti secara harfiah yaitu "diabetes" berarti mengalir dan "Melitus" berarti manis. [2]

Penyakit Diabetes Mellitus sudah dikenal sejak ribuan tahun sebelum masehi, dimana ditandai dengan penderita yang sering kencing dalam jumlah yang banyak. [3] Penderita diabetes dari tahun ke tahun semakin banyak. Hal ini mendorong dilakukan penelitian serius untuk megobati penderitanya. Pengobatan pertama kali penyakit diabetes melitus dilakukan pada tahun 1921 di Kanada dengan menemukan hormon insulin buatan. Lalu pada tahun 1954 ditemukan obat anti diabetes. Penemuan ini memudahkan penggunanya karena praktis dan dapat diatur kadar maupun dosisnya. [4]

Walaupun sudah ada obat ini, penyembuhan total masih belum bisa direalisasikan dengan baik. Hal ini disebabkan fungsi obat ini hanya menurunkan kadar gula darah. [5] Penderita diabetes melitus tetap bertambah dikarenakan perubahan gaya hidup zaman sekarang yang serba instan dan tidak sehat. Cara yang amat baik dalam menekan angka penderita diabetes melitus adalah dengan memberikan informasi pencegahan yang baik. [6]

Berdasarkan masalah di atas maka penulis dapat merumuskan masalah yaitu menganalisis perbandingan penerapan Fuzzy Logic antara metode Mamdani dan Tsukamoto pada kasus menentukan tipe Diabetes Melitus. [7] Sistem yang peneliti rancang ini hanya untuk menentukan tipe Diabetes Melitus yang akan dibahas dalam bentuk Fuzzy Inference System (FIS) dan Output dari rancang bangun sistem ini nanti berupa tipe 1 dan tipe 2.

Tujuan dari penelitian adalah untuk menganalisis dan membandingkan hasil keputusan tipe diabetes menggunakan metode Mamdani dan Tsukamoto serta untuk menguji hasil kalkulasi dengan fuzzy logic kedua metode tersebut dengan hasil keputusan yang sebenarnya pada kasus penentuan tipe diabetes melitus.

\section{Metode Penelitian}

Penjelasan mengenai berbagai komponen yang akan digunakan peneliti serta kegiatan yang akan dilakukan selama proses penelitian dilakukan dengan pendekatan kuantitatif dan kualitatif. Penelitian ini juga dilakukan secara kuantitatif dengan mengambil topik mengenai Artificial Intelegence (brainware).

Penelitian ini memerlukan kerangka kerja agar mendapatkan hasil yang maksimal. Kerangka kerja mencakup langkah-langkah yang dilakukan dalam melakukan penelitian. Penelitian ini memerlukan kerangka kerja berupa langkah-langkah yang akan dilakukan dalam menjawab rumusan masalah sebagai berikut: 


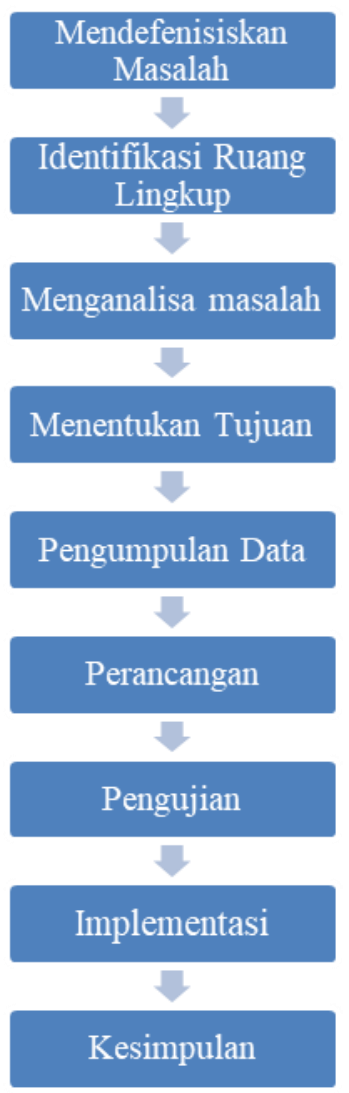

Gambar 1. Desain Penelitian

Keterangan:

1. Mendefenisikan masalah

Dalam hal ini masalah yang sering muncul yaitu bagaimana cara memeilih metode yang paling tepat pada kasus fuzzy logic.

2. Identifikasi ruang lingkup

Penelitian ini hanya mencakup kasus pada pasien penderita diabetes mellitus dengan mengklasifikasi tipenya.

3. Menganalisis masalah

Masalah pemilihan metode ini akan dijelaskan jika dilakukan penelitian pada kasus yang sama dengan metode yang berbeda.

4. Menentukan tujuan

Tujuan utama penelitian ini adalah mencari metode terbaik dalam kasus menentukan tipe diabetes melitus.

5. Pengumpulan data

Data yang diambil yaitu beberapa pasien penderita diabetes melitus di beberapa rumah sakit di Batam.

6. Perancangan

Penelitian ini dilakukan dengan menggunakan software MATLAB

7. Pengujian

Pengujian dilakukan dengan kalkulasi manual beberapa kasus pasien diabetes mellitus.

8. Implementasi

Kalkulasi dilakukan dengan menggunakan rule-rule yang dibentuk dari beberapa sumber pustaka

9. Kesimpulan

Akan ditarik kesimpulan mengenai metode terbaik pada kasus penelitian ini. 
Lokasi Penelitian Kecamatan Sagulung, Batam 20444, Kepulauan Riau. Menurut Patilima supaya data dan informasi dapat dipergunakan dalam penalaran, data dan informasi itu harus merupakan fakta. Di bawah ini dikemukakan beberapa cara yang dipergunakan dalam penelitian penulis, diantaranya:

1. Metode pengamatan

Metode pengamatan merupakan sebuah teknik pengumpulan data yang mengharuskan peneliiti turun ke lapangan mengamati hal-hal yang berkaitan dengan ruang, tempat, pelaku, kegiatan, benda-benda, waktu, peristiwa, tujuan, dan perasaan. Penulis melakukan metode pengamatan dengan cara melihat sistem penentuan tipe diabetes.

2. Wawancara kualitatif

Metode wawancara kualitatif merupakan salah satu teknik untuk mengumpulkan data dan informasi, wawancara yang digunakan adalah wawancara kualitatif, artinya peneliti mengajukan pertanyaan-pertanyaan secara lebih bebas dan leluasa, tanpa terikat oleh suatu susunan pertanyaan yang telah dipersiapkan sebelumnya. Diskusi kelompok terfokus

Diskusi kelompok terfokus merupakan salah satu teknik yang digunakan peneliti untuk menggali data dan informasi mengenai lingkungan kota. Diskusi yang dilakukan oleh peneliti dengan cara observasi dan tanya jawab.

Penelitian ini memerlukan kerangka kerja agar mendapatkan hasil yang maksimal. Kerangka kerja mencakup langkah-langkah yang akan dilakukan dalam melakukan penelitian. Untuk memperolah hasil yang baik diperlukan pembelajaran mengenai masalah yang akan diteliti hingga memperoleh suatu sistem pemecahannya yaitu dapat menentukan tipe diabetes menggunakan fuzzy logic. Sebagai langkah dari penghitungan fuzzy yaitu menentukan himpunan masukan nilai variabel, lalu melakukan fuzzyfikasi, selanjutnya pembentukan aturan fuzzy, berikutnya mencari nilai $\mathrm{Z}$ dengan menggunakan mesin inferensi, dan terakhir defuzzyfikasi menggunakan Metode Mamdani dan Tsukamoto. Variabel fuzzy adalah hasil berbagai jurnal terakreditasi yang nantinya difungsikan sebagai inputan dari mesin inferensi fuzzy. Tabel 1 di bawah ini memaparkan batasan varibel dan himpunan fuzzy sebagai inputan di mesin inferensi fuzzy.

\begin{tabular}{|c|c|c|}
\hline Variabel & Nama Himpunan Fuzzy & Domain \\
\hline \multirow[t]{3}{*}{ Usia } & Anak-anak & {$\left[\begin{array}{ll}0 & 35\end{array}\right]$} \\
\hline & Remaja & [30 70] \\
\hline & Dewasa & {$\left[\begin{array}{ll}65 & 100\end{array}\right]$} \\
\hline \multirow[t]{4}{*}{ Kadar insulin } & Tidak ada & {$\left[\begin{array}{ll}0 & 25\end{array}\right]$} \\
\hline & Rendah & {$\left[\begin{array}{ll}20 & 55\end{array}\right]$} \\
\hline & Normal & [45 80$]$ \\
\hline & Tinggi & {$\left[\begin{array}{ll}75 & 100\end{array}\right]$} \\
\hline \multirow[t]{3}{*}{ Berat badan } & Kurus & {$\left[\begin{array}{ll}0 & 35\end{array}\right]$} \\
\hline & Normal & {$\left[\begin{array}{ll}30 & 70] \\
\end{array}\right.$} \\
\hline & Gemuk & {$\left[\begin{array}{ll}65 & 100\end{array}\right]$} \\
\hline
\end{tabular}

\section{Hasil dan Pembahasan}

Penelitian ini merupakan analisis metode pada Fuzzy logic yang didasari studi pustaka. Hasilnya akan diuji pada MATLAB dengan menggunakan metode Mamdani dan Tsukamoto. Variabel output terdiri dari dua indikator yaitu tipe diabetes I dan tipe diabetes II. [8] Kalkulasi ini akan dibandingkan pada tiga kasus yang berbeda untuk memperoleh analisa yang tajam. 
Tabel 2. Penjabaran langkah kalkulasi Tsukamoto dan Mamdani

\begin{tabular}{|l|l|l|}
\hline \multicolumn{1}{|c|}{ Langkah } & \multicolumn{1}{c|}{ Mamdani } & \multicolumn{1}{c|}{ Tsukamoto } \\
\hline Fuzzyfication & non Fuzzy ke Fuzzy & non Fuzzy ke Fuzzy \\
\hline $\begin{array}{l}\text { Pembentukan } \\
\text { aturan Fuzzy }\end{array}$ & Aturan dalam bentuk if-then & Aturan dalam bentuk if-then \\
\hline $\begin{array}{l}\text { Analisis Logika } \\
\text { Fuzzy }\end{array}$ & $\begin{array}{l}\text { Fungsi implikasi min dengan } \\
\text { komposisi penalaran max }\end{array}$ & $\begin{array}{l}\text { Fungsi implikasi min dengan } \\
\text { komposisi penalaran max }\end{array}$ \\
\hline Defuzzyfikasi & Centroid & Weigthed Average \\
\hline
\end{tabular}

Terdapat tiga variabel input pada penelitian ini yaitu usia, kadar insulin dan berat badan. Masing-masing variabel memiliki tiga indikator. Output pada penelitian ini yaitu tipe diabetes I dan II. Variabel input dan output dibuat pada MATLAB seperti tampak pada Gambar 2.

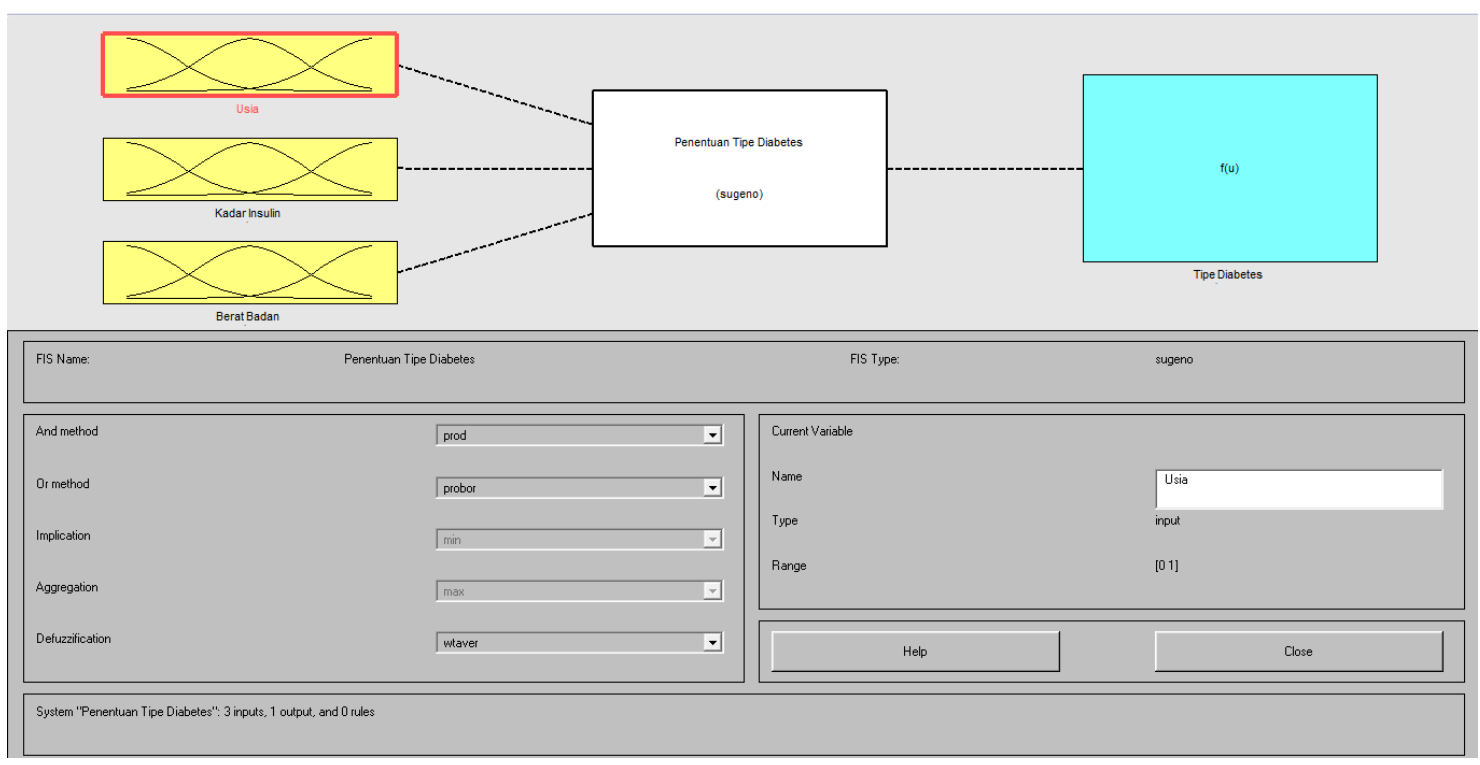

\section{Gambar 2. Variabel Input dan Output}

Aplikasi Fuzzy logic pada penelitian ini memiliki tiga variabel input yang tampak seperti Gambar 2. [9] Ketiga input akan dijelaskan secara rinci sebagai berikut:

1. Usia

Usia merupakan salah satu faktor penentu dalam keputusan tipe diabetes. Pada umumnya penderita diabetes tipe II adalah usia diatas 40 tahun atau tua. Sedangkan untuk tipe diabetes I pada umumnya diderita oleh anak-anak dan dewasa. Oleh karena itu, peneliti membagi tiga indikator pada variabel input usia, yaitu: tua, remaja dan anak-anak.

2. Kadar Insulin

Kadar insulin pada darah juga dipakai sebagai tolak ukur penentu tipe diabetes. Insulin adalah hormon yang bertanggung jawab mengatur kadar glukosa darah sebagai bagian dari metabolisme tubuh. Penderita diabetes tipe II memiliki kadar insulin yang tinggi. Dalam hal ini penulis membagi variabel kadar insulin dalam tiga indikator yaitu: rendah, sedang dan tinggi.

3. Berat Badan

Penderita diabetes tipe I umumnya memilki berat badan yang ideal bahkan kurus. Berbeda dengan penderita diabetes tipe II umumnya memiliki berat badan yang besar atau gemuk. Variabel Berat Badan dibagi menjadi tiga indikator, yaitu: gemuk, normal dan kurus 
Agar lebih memahami klasifikasi variabel dan indikator yang digunakan dalam penelitian ini, maka dibuat sebuah diagram yang menjelaskan analisis variabel input Fuzzy metode Sugeno seperti pada Gambar 3.
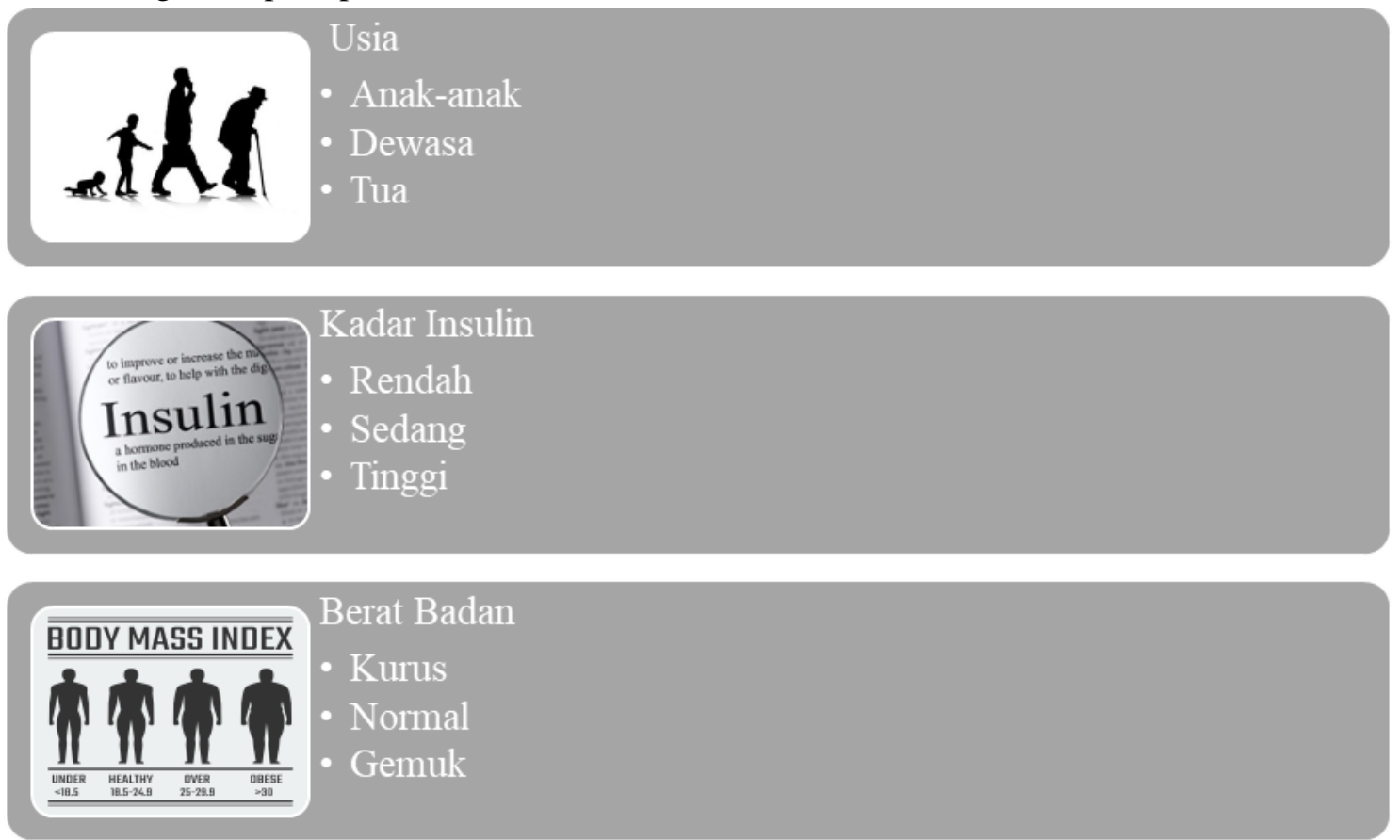

Gambar 3. Proses Analisis Variabel Input Fuzzy

Pada proses Fuzzyfucation, harus ditentukan semesta pembicaraan dimana dalam kasus ini terdapat 3 variabel input, yaitu usia, kadar insulin dan berat badan. Sedangkan untuk output berupa keputusan yaitu tipe diabetes penderita. Agar lebih dapat dipahami, akan dibentuk semesta pembicaraan pada tiap variabel seperti yang terlihat pada Tabel 3 berikut ini.

Tabel 3. Semesta Pembicaraan

\begin{tabular}{|l|l|l|}
\hline \multirow{3}{*}{ Fungsi } & Nama Variabel & Semesta Pembicaraan \\
\hline \multirow{3}{*}{ Input } & Usia & {$\left[\begin{array}{ll}0 & 100\end{array}\right]$} \\
\cline { 2 - 3 } & Kadar Insulin & {$\left[\begin{array}{ll}0 & 100\end{array}\right]$} \\
\cline { 2 - 3 } & Berat Badan & {$\left[\begin{array}{ll}0 & 100\end{array}\right]$} \\
\hline Output & Tipe Diabetes & {$\left[\begin{array}{ll}0 & 100\end{array}\right]$} \\
\hline
\end{tabular}

Semua variabel baik input maupun output memiliki semesta pembicaraan 0 sampai dengan 100. Tabel 3 merupakan tabel domain himpunan Fuzzy menjelaskan rentang yang digunakan dalam penelitian ini.

Setiap aturan harus memiliki implikasi. Implikasi berbentuk operator yang dalam hal ini digunakan dua operator yaitu, AND untuk menghubungkan antara dua masukan dan IF-THEN untuk memetakan antara masukan dan keluaran. Aturan-aturan yang ada pada kasus penelitian ini dibuat pada MATLAB seperti pada Gambar 4. 


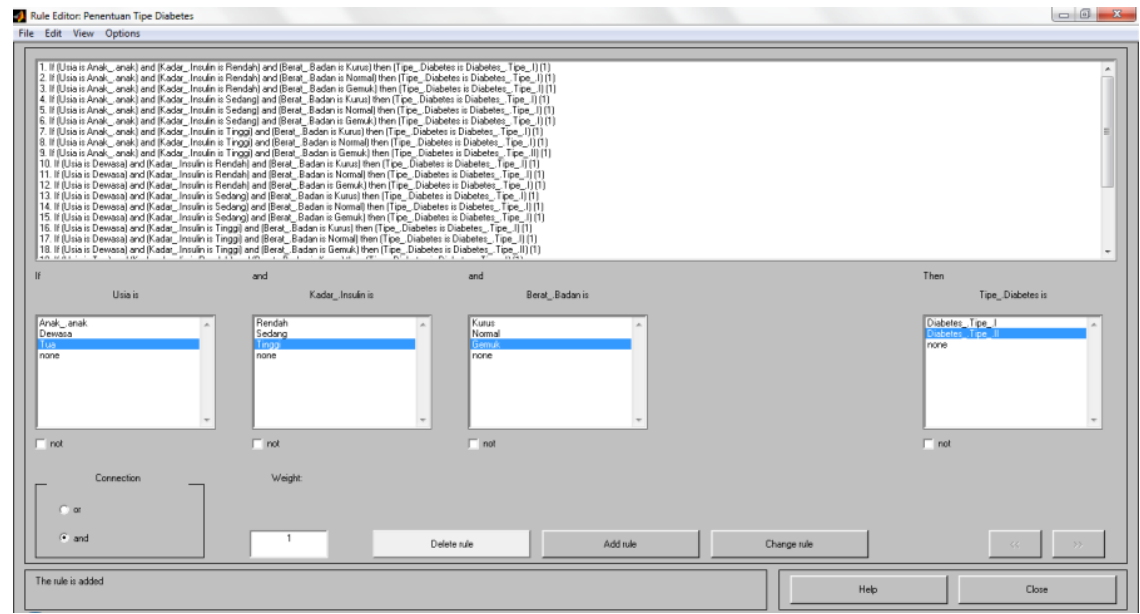

Gambar 4. Rules penentuan Tipe Diabetes pada MATLAB

Berdasarkan Rules yang telah dijabarkan sebelumnya, maka tampak bahwa pada penelitian ini digunakan rules sebanyak 27.

Pada penelitian ini dilakukan tiga studi kasus sebagai bahan uji aplikasi yang telah dibuat. Studi kasus tersebut antara lain:

\section{Kasus I}

Orang tua seorang pasien merasa anaknya terkena penyakit diabetes karena faktor turunan ingin mengetahui tipe diabetes sang anak. Pasien ini masih berumur 10 tahun. Setelah diukur kadar insulinnya bernilai $6,7 \mathrm{mmol} / \mathrm{L}$. Anak ini memiliki tubuh yang gemuk dengan BMI 27. Berdasarkan kasus tersebut maka, variabel yang diberikan antara lain usia $=24$, kadar insulin $=66$ dan berat badan $=90$. Sebelum dilakukan interferensi perlu dicari terlebih dahulu derajat keanggotaan nilai tiap variabel dalam setiap himpunan.

a. Usia

- $\mu$ Anak-anak $[x] \quad=(40-x) /(40-20)$

$\mu$ Anak-anak $[24] \quad=(40-24) /(40-20)$

$=16 / 20$

$=0,8$

- $\mu$ Dewasa [24] $\quad=0$

- $\mu$ Tua [24] $=0$

b. Kadar Insulin

- $\mu$ Rendah [66] $\quad=0$

- $\mu$ Sedang $[x] \quad=(70-x) /(70-50)$

$\mu$ Sedang $[66] \quad=(70-66) /(70-50)$

$=4 / 20$

$=0,2$

- $\mu$ Tinggi $[x] \quad=(x-60) /(80-60)$

$\mu$ Tinggi $[66] \quad=(66-60) /(80-60)$

$=6 / 20$

$=0,3$

c. Berat Badan

- $\mu$ Kurus [90] $\quad=0$

- $\mu$ Normal [90] $\quad=0$

- $\mu$ Gemuk [90] $=1$

Langkah selanjutnya adalah mencari $\alpha$-predikat dari tiap-tiap rule: 
[R1] IF (Usia Anak-anak) AND (Kadar Insulin Rendah) AND (Berat Badan Kurus) THEN (Diabetes Tipe I)

$\alpha$-predikat $_{1} \quad=\mu$ Anak-anak $\cap \mu$ Rendah $\cap \mu$ Kurus

$$
\begin{aligned}
& =\min (\mu \text { Anak-anak [24], } \mu \text { Rendah [66], } \mu \text { Kurus [90] }) \\
& =\min (0,8 ; 0 ; 0) \\
& =0
\end{aligned}
$$

$\alpha$-predikat untuk [R2] sampai dengan [R5] $=0$

[R6] IF (Usia Anak-anak) AND (Kadar Insulin Sedang) AND (Berat Badan Gemuk) THEN (Diabetes Tipe I)

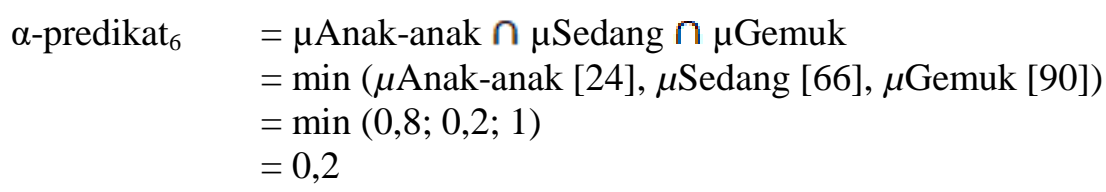

$\alpha$-predikat untuk [R7] sampai dengan [R8] $=0$

[R9] IF (Usia Anak-anak) AND (Kadar Insulin Tinggi) AND (Berat Badan Gemuk) THEN (Diabetes Tipe II)

$$
\begin{aligned}
\alpha \text {-predikat }_{9} & =\mu \text { Anak-anak } \cap \mu \text { Tinggi } \cap \mu \text { Gemuk } \\
& =\min (\mu \text { Anak-anak [24], } \mu \text { Tinggi [66], } \mu \text { Gemuk [90] }) \\
& =\min (0,8 ; 0,3 ; 1) \\
& =0,3
\end{aligned}
$$

$\alpha$-predikat untuk [R10] sampai dengan $[\mathrm{R} 27]=0$

\section{Kasus II}

Seseorang yang merasa dirinya terkena diabetes ingin mengetahui tipe diabetes yang dideritanya. Orang tersebut berumur 25 tahun. Setelah diukur kadar insulinnya lumayan tinggi yaitu bernilai $6,6 \mathrm{mmol} / \mathrm{L}$. Pasien ini memiliki tubuh yang gemuk dengan BMI 26. Berdasarkan kasus tersebut maka, variabel yang diberikan antara lain usia $=40$, kadar insulin $=62$ dan berat badan $=74$. Sebelum dilakukan interferensi perlu dicari terlebih dahulu derajat keanggotaan nilai tiap variabel dalam setiap himpunan.

\section{Kasus III}

Pasien yang telah lama menderita diabetes ingin mengecek kembali tipe diabetes yang dideritanya. Orang tersebut berumur 43 tahun. Setelah diukur kadar insulinnya lumayan tinggi yaitu bernilai $6,7 \mathrm{mmol} / \mathrm{L}$. Pasien ini memiliki tubuh yang relatif kurus dengan BMI 19. Berdasarkan kasus tersebut maka, variabel yang diberikan antara lain usia $=64$, kadar insulin $=66$ dan berat badan $=22$. Sebelum dilakukan interferensi perlu dicari terlebih dahulu derajat keanggotaan nilai tiap variabel dalam setiap himpunan.

\section{Defuzzyfikasi Mamdani}

\section{Kasus I}

Dari hasil aplikasi fungsi implikasi dari tiap aturan, digunakan metode MAX untuk melakukan komposisi antar semua aturan. Hasilnya seperti pada Gambar 5 


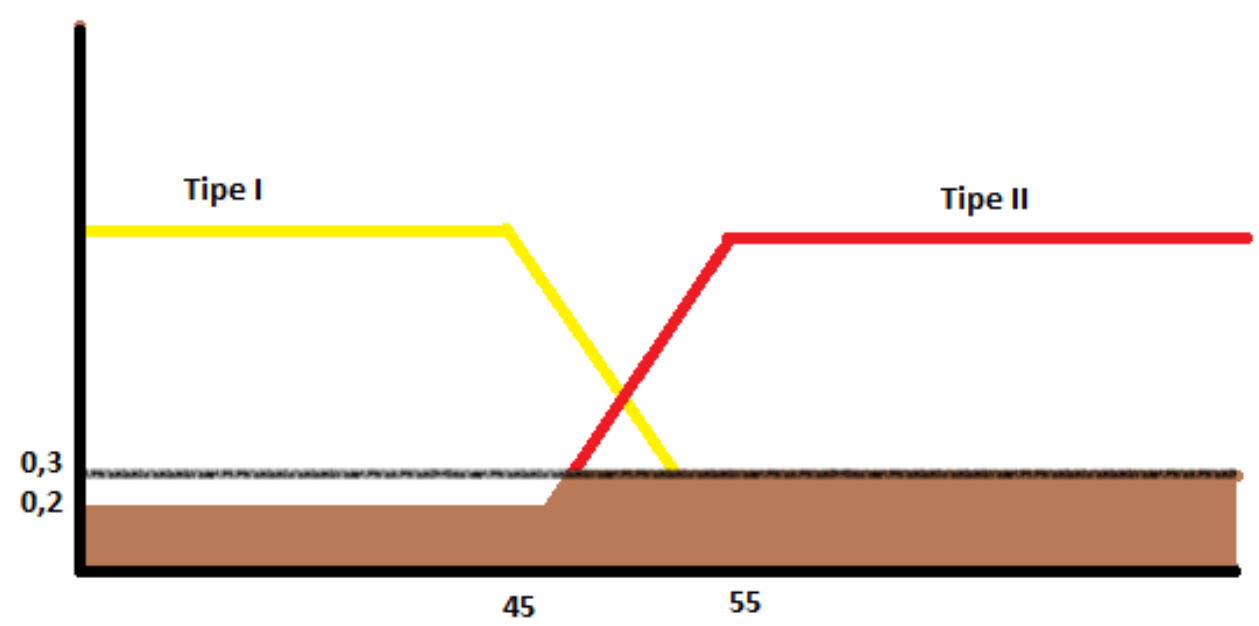

Gambar 5. Daerah Hasil Komposisi Kasus I

Pada Gambar 5 tersebut, daerah hasil dibagi menjadi 3 bagian, dimana fungsi keanggotaan untuk hasil komposisi ini adalah:

$$
\mu[\mathrm{z}]=\left\{\begin{array}{l}
0,2 ; 0 \leq z \leq 47 \\
(z-45) / 10 ; 47 \leq z \leq 48 \\
0.3 ; 48 \leq z \leq 100
\end{array}\right.
$$

Metode penegasan yang digunakan adalah metode Centroid. Untuk itu, langkah pertama yaitu dihuitung momen untuk setiap daerah.

$$
\begin{aligned}
& M 1=\int_{0}^{47} 0.2 z d z=0.1 z^{2}(z=47-z=0)=220,9 \\
& M 1=\int_{47}^{47}\left(0.1 z^{2}-4,5 z\right) d z=0.033 z^{3}-2,25 z^{2}(z=48-z=47)=9,6 \\
& M 2=\int_{48}^{100} 0.3 z d z=0.15 z^{2}(z=100-z=48)=1154,4
\end{aligned}
$$

Kemudian dihitung luas tiap daerah:

$$
\begin{aligned}
& \text { A1 }=0,2 \times 47=9,4 \\
& \text { A2 }=(0,2+0,3) \times 1 / 2=0,25 \\
& \text { A3 }=(100-48) \times 0,3=15,6
\end{aligned}
$$

Titik pusat dapat diperoleh dari:

$$
z=\frac{220,9+9,6+1154,4}{9,4+0,25+15,6}=\frac{1384,9}{25,25}=55,85
$$

Jadi dapat disimpulkan bahwa pada kasus pertama, pasien memiliki penyakit diabetes tipe II dengan nilai $\mathrm{z}=55,85$ 


\section{Defuzzyfikasi Tsukamoto}

\section{Kasus I}

Langkah awal logika Fuzzy menggunakan metode Tsukamoto yaitu mencari nilai z untuk setiap aturan dengan menggunakan fungsi MIN pada aplikasi fungsi implikasinya:

[R1] IF (Usia Anak-anak) AND (Kadar Insulin Rendah) AND (Berat Badan Kurus) THEN (Diabetes Tipe I)

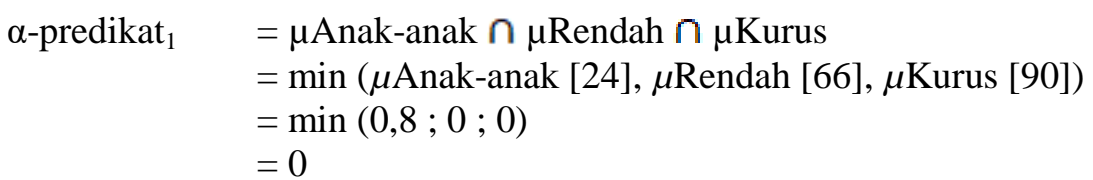

Nilai $\mathrm{z}_{1}$ tidak perlu dicari karena $\alpha$-predikat nya bernilai 0

$\alpha$-predikat untuk [R2] sampai dengan [R5] $=0$, maka nilai $\mathrm{z}_{2}$ sampai dengan $\mathrm{z}_{5}$ tidak perlu dicari karena $\alpha$-predikat nya bernilai 0

[R6] IF (Usia Anak-anak) AND (Kadar Insulin Sedang) AND (Berat Badan Gemuk) THEN (Diabetes Tipe I)

$$
\begin{aligned}
\alpha_{- \text {predikat }_{6}} & =\mu \text { Anak-anak } \cap \mu \text { Sedang } \cap \mu \text { Gemuk } \\
& =\min (\mu \text { Anak-anak [24], } \mu \text { Sedang [66], } \mu \text { Gemuk [90] }) \\
& =\min (0,8 ; 0,2 ; 1) \\
& =0,2
\end{aligned}
$$

Dicari nilai $\mathrm{z}_{6}$,$$
(55-\mathrm{z}) / 10=0,2 \rightarrow \mathrm{z}_{6}=53
$$

$\alpha$-predikat untuk [R7] sampai dengan [R8] $=0$, maka nilai $\mathrm{z}_{7}$ sampai dengan $\mathrm{z}_{8}$ tidak perlu dicari karena $\alpha$-predikat nya bernilai 0

[R9] IF (Usia Anak-anak) AND (Kadar Insulin Tinggi) AND (Berat Badan Gemuk) THEN (Diabetes Tipe II)

$$
\begin{aligned}
\alpha \text {-predikat }_{9} & =\mu \text { Anak-anak } \cap \mu \text { Tinggi } \cap \mu \text { Gemuk } \\
& =\min (\mu \text { Anak-anak [24], } \mu \text { Tinggi [66], } \mu \text { Gemuk [90] }) \\
& =\min (0,8 ; 0,3 ; 1) \\
& =0,3
\end{aligned}
$$

Dicari nilai $\mathrm{Z}_{9}$,

$$
(\mathrm{z}-45) / 10=0,3 \rightarrow \mathrm{z}_{6}=48
$$

$\alpha$-predikat untuk [R10] sampai dengan [R27] $=0$, maka nilai $\mathrm{z}_{10}$ sampai dengan $\mathrm{z}_{27}$ tidak perlu dicari karena $\alpha$-predikat nya bernilai 0

Setelah memperoleh nilai $\mathrm{z}$ dari masing-masing aturan, maka nilai $\mathrm{z}$ total untuk kasus I ini adalah:

$$
\begin{aligned}
& z=\frac{\alpha-\text { predikat }_{1} * z_{1}+\alpha-\text { predikat }_{2} * z_{2}+\cdots+\alpha-\text { predikat }_{27} * z_{27}}{\alpha-\text { predikat }_{1}+\alpha-\text { predikat }_{2}+\cdots+\alpha-\text { predikat }_{27}} \\
& z=\frac{0 * 0+\cdots+0,2 * 53+\cdots+0,3 * 48+\cdots}{0+\cdots+0,2+\cdots+0,3+\cdots} \\
& z=\frac{10,6+14,4}{0,5}=50
\end{aligned}
$$


Jadi tidak dapat disimpulkan bahwa pada kasus pertama, pasien memiliki penyakit diabetes tipe I atau tipe II karena nilai $\mathrm{z}=50$

Perbandingan hasil perhitungan manual menggunakan metode Mamdani dan Tsukamoto pada tiga kasus penentuan tipe diabetes dengan keadaan sebenarnya diperlihatkan pada Tabel 4 berikut ini:

Tabel 4. Perbandingan hasil Metode Mamdani dan Tsukamoto

\begin{tabular}{|c|c|c|c|c|c|c|c|c|}
\hline \multirow{2}{*}{ Kasus } & \multicolumn{3}{|c|}{ Input } & \multicolumn{4}{|c|}{ Output } & \multirow{2}{*}{$\begin{array}{c}\text { Kasus } \\
\text { nyata }\end{array}$} \\
\hline & Usia & Insulin & Berat & Tsukamoto & Tipe & Mamdani & Tipe & \\
\hline $\bar{I}$ & 24 & 66 & 90 & 50.00 & - & 55.85 & II & II \\
\hline II & 40 & 62 & 74 & 50.00 & - & 14.33 & I & I \\
\hline III & 64 & 66 & 22 & 51.30 & II & 45.17 & I & I \\
\hline
\end{tabular}

Berdasarkan Tabel 4 terlihat bahwa penggunaan Fuzzy logic menggunakan metode Mamdani lebih tepat dalam kasus penentuan tipe diabetes dibandingkan dengan metode Tsukamoto. Berdasarkan kalkulasi yang telah dilakukan perbedaan hasil keluaran yang signifikan ini disebabkan oleh beberapa hal, diantaranya:

1. Output yang ada pada Tsukamoto hanya berkisar pada nilai 45 sampai dengan 55. Dimana nilai itu adalah nilai keraguan antara dua variabel output tipe diabetes. Hal ini berbeda dengan metode Mamdani yang secara jelas memberikan output antara 0 sampai dengan 100. Semakin besar rentang keluaran, maka keputusan akan semakin mudah diperoleh.

2. Pada metode Tsukamoto jika terdapat dua ouput maka cenderung akan mendapatkan nilai mendekati pertengahan yaitu 50. Hal ini membuat jika sedikit saja kalkulasi salah maka hasil yang diperoleh akan berdampak besar. Sedangkan hal ini tidak akan berlaku pada metode Mamdani.

3. Pada metode Tsukamoto, kalkulasi dilakukan pada setiap aturan yang memiliki nilai alfa prediket. Sedangkan pada metode Mamdani hanya yang bernilai maksimum untuk tiap variabel output.

Hal inilah yang menyebabkan Matlab tidak memberikan aplikasi perhitungan logika Fuzzy menggunakan metode Tsukamoto, karena Metode Mamdani telah diperbaharui cara kalkulasinya agar sesuai dengan keadaan sebenarnya. Walaupun proses kalkulasi metode Mamdani membutuhkan waktu yang lama, tetapi hasil yang diberikan lebih optimal.

\section{Kesimpulan}

Berdasarkan hasil penelitian yang telah dilakukan, maka dapat diambil kesimpulan bahwa Penggunaan fuzzy logic menggunakan metode Mamdani lebih optimal dalam kasus penentuan tipe diabetes dibandingkan dengan metode Tsukamoto. Hasil kalkulasi manual menunjukan bahwa metode Mamdani lebih mendekati keadaan yang sebenarnya. Walaupun proses kalkulasi metode Mamdani membutuhkan waktu yang lama, tetapi hasil yang diberikan lebih tepat.

\section{Daftar Pustaka}

[1] Laras Purwati Ayuningtias, Mohamad Irfan, J. Analisa Perbandingan Logic Fuzzy Metode Tsukamoto, Sugeno, Dan Mamdani (Studi Kasus : Prediksi Jumlah Pendaftar Mahasiswa Baru Fakultas Sains Dan Teknologi Universitas Islam Negeri Sunan Gunung Djati Bandung). 2017. Jurnal Teknik Informatika, 19.

[2] Hanna, V. Hubungan Pengendalian Diabetes Mellitus Dengan Kadar Glukosa Darah Pada Pasien Diabetes Mellitus Di Rsud Manembo Nembo Bitung. 2013. Jurnal Keperawatan, 
$1(1), 1-7$.

[3] Hoffman, W. Markers Of Immune-Mediated Inflammation In The Brains Of Young Adults And Adolescents With Type 1 Diabetes And Fatal Diabetic Ketoacidosis. 2017. Experimental and Molecular Pathology, 1-42.

[4] Harfika, M. Karakteristik Penderita Diabetes Melitus Tipe 2 Di Instalasi Rawat Inap Penyakit Dalam Rumah Sakit Mohammad Hoesin Palembang. 2015. Palembang.

[5] Damanik, B. Sistem Pendukung Keputusan Terapi Penderita Diabetes Melitus Type 2 Dengan Metode Fuzzy Tsukamoto. 2015. Jurnal Pendidikan Teknologi Dan Kejuruan, 1723.

[6] Ernawati. Penatalaksanaan Keperawatan Diabetes Melitus Terpadu (1st ed.). 2013. Jakarta: Mitra Wacana Media.

[7] Merino, M. Research Risk Factors For Diabetic Macular Oedema In Type 2 diabetes: A Case-Control Study In A United Kingdomprimary Care Setting. 2017. Primary Case Diabetes, $1-9$.

[8] Latu Handarko, J. mplementasi Fuzzy Decision Tree Untuk Mendiagnosa Penyakit Hepatitis. UNNES Journal of Mathematics, 2015. 4(2), 15-164.

[9] Kamat, Y. Distinct Clinical Characteristics And Therapeutic Modalities For Diabetic Ketoacidosis In Type 1 And Type 2 Diabetes Mellitus. 2016. Jurnal of Diabetes and Its Complications, 1-22. https://doi.org/10.1016/j.jdiacomp.2016.06.023 